Announcements

\title{
Special Issue on Discrimination
}

Law and Human Behavior is planning a special issue dealing with discrimination and the law. Scientific research on issues of discrimination is increasingly introduced into legal settings. This work comes from a variety of disciplines and raises numerous issues. The planned volume will include articles based on original research as well as review essays, dealing with issues of sex, age, race, class, and other kinds of discrimination handled in various legal settings. The focus will be multidisciplinary and, conceivably, cross-national. Please send concept papers and/or manuscripts to the guest editor for this issue, John Hagan, Faculty of Law, University of Toronto, Toronto, Ontario, Canada, M5S 1A1.

\section{Postdoctoral Program}

The School of Urban and Public Affairs at Carnegie-Mellon University is offering a unique postdoctoral program in Quantitative Methods in Criminal Justice. This program is intended to bring together specialists in disciplines related to the problems of crime and criminal justice with persons whose principal training is in methodology. The participants will engage in an active empirical research program, with access to a number of fundamental data sets that are now available; a joint seminar focusing on research approaches to the phenomena involved in criminal justice and relevant policy issues; and relevant methodological techniques. In addition to a stipend of at least $\$ 13,380$ (depending on years of postdoctoral experience), all training costs and research resources are provided. A limited number of predoctoral fellowships are also available to individuals who have already completed at least two years of graduate study. For further information, and for application forms, please write to: Professor Alfred Blumstein, School of Urban and Public Affairs, Carnegie-Mellon University, Pittsburgh, Pennsylvania 15213. 